Pathophysiology of Haemostasis and Thrombosis
Pathophysiol Haemost Thromb 2005;34:1-5

DOI: $\underline{10.1159 / 000088540}$
Received: January 11, 2005

Accepted after revision: March 21, 2005

\title{
Platelet Activation Markers in Patients with Venous Thromboembolism without Predisposing Factors
}

\author{
Frank Gerdsen $^{\mathrm{a}}$ Martin Weber ${ }^{\mathrm{b}}$ Florian Langer ${ }^{\mathrm{c}}$ Barbara Eifrig $^{\mathrm{c}}$ \\ Edelgard Lindhoff-Last ${ }^{d}$
}

\begin{abstract}
${ }^{a}$ Vascular Centre Berlin, Department of Internal Medicine, Evangelisches Krankenhaus Königin Elisabeth Herzberge, Berlin, Germany; ${ }^{b}$ Department of Molecular and Experimental Medicine, The Scripps Research Institute, La Jolla, Calif., USA; ' Division of Oncology and Haematology, Department of Internal Medicine, University Hospital Hamburg-Eppendorf, Hamburg, and ${ }^{\mathrm{d}}$ Division of Angiology, Department of Internal Medicine, University Hospital Frankfurt, Germany
\end{abstract}

\section{Key Words}

Venous thromboembolism · Platelets · Flow

cytometry $\cdot$ Risk factor

\begin{abstract}
A constant in vitro hypersensitivity of platelets (adenosine diphosphate) has been suggested as a risk factor for arterial and even venous thrombosis. Our aim was to determine phenotypic and functional alterations of platelets by flow cytometry as potential prothrombotic risk factors in patients with a history of unexplained spontaneous venous thrombosis. Forty-nine patients with a history of spontaneous venous thrombosis and no inherited or acquired thrombophilic risk factors were compared with a reference group of 39 healthy volunteers. Flow cytometry (FACS) was used to analyze the surface expression of CD62 (P-selectin) and CD63 in nonactivated platelets and after in vitro stimulation with adenosine diphosphate and thrombin receptor activator peptide 6 . Mean fluorescence intensity of CD62 and CD63 surface expression as well as percentage of CD62 and CD63 positive cells and binding index differed in patients with a history of thrombosis compared with the reference group, but failed to reach statistical significance. Similar
\end{abstract}

results were observed after in vitro stimulation with adenosine diphosphate and thrombin receptor activator peptide 6 . In conclusion, the expression of CD62 and CD63 of resting and in vitro activated platelets could not be established as a risk factor for spontaneous venous thromboembolism.

Copyright (C) 2005 S. Karger AG, Basel

\section{Introduction}

Thrombosis is now understood as a multifactorial event. Apart from exogenous risk factors like surgery, immobilization, pregnancy or malignancy, a number of inherited or acquired abnormalities of the coagulation system have been identified as risk factors for venous thromboembolism (VTE). Dysfunction of the plasmatic coagulation characterized by an imbalance of the clotting cascade and the fibrinolytic system has been well defined by several pathological findings like deficiency of protein $\mathrm{C}$, protein $\mathrm{S}$ and antithrombin deficiency, resistance to activated protein $\mathrm{C}$, mutation of the prothrombin gene at position G20210A or antiphospholipid antibodies. Less is known about the role of the cellular side of the coagulation system in the setting of venous thrombosis. Few stud-

\section{KARGER}

Fax +4161306 1234 E-Mail karger@karger.ch www.karger.com 
ies have focused on platelet abnormalities as predisposing factors for thrombosis. One of the first reports by Wu et al. [1] suggested that enhanced platelet aggregation in platelet aggregometry might be an important risk factor for recurrent venous thrombosis. Breddin et al. [2] demonstrated a positive correlation between spontaneously enhanced platelet aggregation and vascular occlusions. Similar findings were observed for idiopathic thrombosis in childhood [3]. Prospective data from 148 patients with arterial or venous thrombosis showed an enhanced spontaneous platelet aggregation in $55-75 \%$ during the 3 months prior to the event [4]. Mammen et al. [5] described hyperreagibility of platelets to low concentrations using platelet aggregometry of epinephrine or adenosine diphosphate (ADP) as a risk factor in over 200 families with a wide variety of arterial and venous thrombosis. This entity with the evidence of an autosomal dominant inheritance was termed the 'sticky platelet syndrome'.

Flow cytometry has been established as a sensitive tool for characterization of platelet function in prothrombotic conditions like diabetes, antiphospholipid antibody syndrome, heparin-induced thrombocytopenia type II, acute myocardial infarction and acute ischemic cerebrovascular disease leading to platelet activation [6-10]. The aim of the study was to evaluate whether FACS analysis of platelet activation markers ex vivo and after in vitro stimulation indicates a permanent prothrombotic state in patients with a history of otherwise unexplained VTE.

\section{Material and Methods}

\section{Study Population}

The study population consisted of 49 patients with a history of VTE. They were consecutively recruited at the outpatient department of the University Hospital Hamburg-Eppendorf between January 1999 and December 2001. The following criteria lead to inclusion into the study population: a history of spontaneous VTE, without abnormal findings concerning protein $\mathrm{C}$, protein $\mathrm{S}$, antithrombin activity, activated protein $\mathrm{C}$ resistance, prothrombin mutation, homocysteine levels, lupus anticoagulants or anticardiolipin antibodies. Platelet aggregation inhibitors were stopped at least 10 days prior to investigation.

Investigations were carried out for at least 6 weeks, in the average 22.3 weeks (range 8-73) after the thrombotic event. Patients' characteristics are given in table 1.

\section{Control Group}

Thirty-nine healthy blood donors with no history of venous thrombosis were recruited as a control group. In this group, the medical history was evaluated by a questioner to exclude underlying acute or chronic circumstances being a cause for platelet activation (table 1). Age and sex distributions were similar for patients
Table 1. Characteristics of patients and controls

\begin{tabular}{llll}
\hline & $\mathrm{n}$ & $\begin{array}{l}\text { Age, years } \\
(\text { mean } \pm \mathrm{SD})\end{array}$ & Male/female \\
\hline Patients & 49 & $48.7 \pm 12.8$ & $22 / 27$ \\
Controls & 39 & $45.7 \pm 10.3$ & $17 / 22$ \\
\hline
\end{tabular}

with a history of spontaneous venous thrombosis and the control group of healthy volunteers (table 1).

\section{Collection of Blood Samples}

All investigated individuals were at rest for at least $15 \mathrm{~min}$ before blood collection. Blood samples were obtained by a sharp antecubital venipuncture using a 21-gauche needle (Sarstedt, Nürnbrecht, Germany) and collected in polypropylen monovettes (Sarstedt) containing 3.2\% sodium citrate.

\section{In vitro Stimulation of Platelets}

For in vitro stimulation of platelets, citrated whole blood was incubated with the agonists ADP $5 \mu M$ (Biodata, Germany) and thrombin receptor-activating peptide 6(TRAP-6) $10 \mu M$ (SLFFRN, Bachem, Heidelberg, Germany) for 5 min before fixation.

\section{Preparation of Blood Samples for Flow Cytometry}

Platelets were immediately fixated by a 10 -min incubation in $0.15 M$ phosphate-buffered saline (Gibco BRL, Eggenstein, Germany) containing $0.2 \%$ v/v glyoxal (Merck, Darmstadt, Germany) and $0.4 \mathrm{w} / \mathrm{v}$ paraformaldehyde (Merck). Samples were stabilized by 10 -fold dilution with phosphate-buffered saline containing $0.2 \%$ w/v glycine (Serva, Heidelberg, Germany). For flow cytometric analysis, $100 \mu \mathrm{l}$ of each sample was labeled with saturating concentrations of monoclonal antibodies for $30 \mathrm{~min}$ at room temperature in the dark.

\section{Monoclonal Antibodies}

To detect platelet activation, murine monoclonal antibodies against P-selectin (CD62p) and CD63 (Coulter-Immunotech, Krefeld, Germany) were used. CD41a (GP IIb/IIIa) was used as a tagging antibody. A nonspecific antibody (Coulter-Immunotech, Hamburg, Germany) was used to detect nonspecific staining. All antibodies were of the IgG isotype and directly conjugated with either fluorescein isothiocyanate or phycoerythrin and originated from the same lot.

\section{Flow Cytometry}

A FACSCalibur ${ }^{\circledR}$ from Becton Dickinson, Heidelberg, Germany, was used for flow cytrometric analysis. CELLQuest ${ }^{\circledR}$ software (Becton Dickinson) was used for acquisition and analysis of listmode data. Platelets were detectable in dotplots of log forwardangle light scatter versus $\log 90^{\circ}$ side scatter. An appropriate threshold was set in the forward scatter to exclude debris and electronic noise. Fluorescein isothiocyanate and phycoerythrin fluorescence were displayed on logarithmic scales, and 10,000 events were analyzed for each sample. Results were expressed in arbitrary mean fluorescence intensity (MFI) and percentage of positive platelets (PPP), calculated by subtracting the nonspecific fluorescence of the 
isotype control from the specific fluorescence of the monoclonal antibodies. For subtraction, the manufacturer's software was used (CELLQuest software, Becton Dickinson).

\section{Statistical Analysis}

SPSS $10.1^{\circledR}$ software (SPSS Inc., Chicago, Ill., USA) was used for statistical analysis. Comparisons of the data were performed using the U test (Mann-Whitney test) for paired non-Gaussian data. A p value $<0.05$ was considered to be statistically significant. Results of corpuscular MFI and PPP are indicated as medians and percentiles.

\section{Results}

\section{Clinical Characteristics of the Patients}

Twenty-six (53.1\%) of the 49 patients had experienced a deep vein thrombosis within the last months. Eight $(16.3 \%)$ presented with isolated pulmonary embolism and $9(18.4 \%)$ had both. Sinus vein thrombosis was observed in 5 patients $(10.2 \%)$. Twelve patients $(24.5 \%)$ presented with recurrent thromboembolic complications (table 2).

\section{Ex vivo Measurements in Resting Platelets}

The median of the MFI of CD62 and the PPP for CD62 ex vivo were slightly higher in patients with thromboembolism compared with the control group (MFI: median 28.4 vs. $27.0, \mathrm{p}=0.33$; PPP: median 2.9 vs. $2.6, \mathrm{p}=$ 0.97), whereas for CD63 antigen, MFI (median 42.2 vs. 42.4, $\mathrm{p}=0.88$ ) and PPP (median 11.1 vs. $12.3, \mathrm{p}=0.75$ ) were higher in the control group. No significant differences between groups were observed (table 3 ).

\section{In vitro Stimulation with $A D P$ and TRAP-6}

A higher increase in ADP-induced expression of CD62 antigen was observed in the study population group (MFI: median 76.3 vs. $76.2, \mathrm{p}=0.33$; PPP: median 4.8 vs. 3.2 , $\mathrm{p}=0.13$ ). Activation-dependent binding sites of CD63 increased slightly more in the patients' group (MFI: median 106.1 vs. 99.6, $\mathrm{p}=0.51$ ), whereas PPP for CD63 stayed lower in the patients' group in comparison with the control group (median 9.8 vs. 10.9, $\mathrm{p}=0.59$ ).

Activation with TRAP-6 resulted in a higher amount of positive cells for both CD62 (median 42.0 vs. 39.4, $\mathrm{p}=0.89$ ) and CD63 (median 42.0 vs. 39.6, $\mathrm{p}=0.53$ ) in the patients' group, whereas a more pronounced increase in MFI could be observed in the control group for both applied markers (CD 62: median 254.1 vs. $266.1, \mathrm{p}=$ 0.48; CD 63: median 253.3 vs. $265.0, p=0.62$ ). None of the investigated parameters reached statistical significance (table 4,5$)$.
Table 2. Type of thrombosis

\begin{tabular}{lrr}
\hline Type of thrombosis & $\mathrm{n}$ & $\%$ \\
\hline Deep vein thrombosis & $26 / 49$ & 53.1 \\
Pulmonary embolism & $8 / 49$ & 16.3 \\
Pulmonary embolism + deep vein thrombosis & $9 / 49$ & 18.4 \\
Sinus vein thrombosis & $5 / 49$ & 10.2 \\
Recurrent venous thrombosis & $12 / 49$ & 24.5 \\
\hline
\end{tabular}

Table 3. MFI and PPP in patients with thromboembolism and controls before in vitro stimulation (medians and percentiles)

\begin{tabular}{|c|c|c|c|c|}
\hline \multirow[t]{2}{*}{ Marker } & \multicolumn{2}{|l|}{ MFI } & \multicolumn{2}{|l|}{ PPP } \\
\hline & CD62 & CD63 & CD62 & CD63 \\
\hline \multicolumn{5}{|c|}{ Venous thrombosis group $(n=49)$} \\
\hline Median & 28.4 & 42.1 & 2.9 & 11.1 \\
\hline 25 th & 23.1 & 37.0 & 1.4 & 8.0 \\
\hline 75 th & 31.4 & 47.1 & 4.8 & 14.3 \\
\hline \multicolumn{5}{|c|}{ Control group $(\mathrm{n}=39)$} \\
\hline Median & 27.0 & 42.4 & 2.6 & 12.3 \\
\hline 25 th & 22.8 & 36.6 & 1.7 & 5.7 \\
\hline 75 th & 29.7 & 49.4 & 4.1 & 14.5 \\
\hline $\mathrm{p}$ value & 0.33 & 0.88 & 0.97 & 0.75 \\
\hline
\end{tabular}

Table 4. MFI and PPP in patients with thromboembolism and controls after in vitro stimulation with ADP (medians and percentiles)

\begin{tabular}{|c|c|c|c|c|}
\hline \multirow[t]{2}{*}{ Marker } & \multicolumn{2}{|l|}{ MFI } & \multicolumn{2}{|l|}{ PPP } \\
\hline & CD62 & CD63 & CD62 & CD63 \\
\hline \multicolumn{5}{|c|}{ Venous thrombosis group $(n=49)$} \\
\hline Median & 76.3 & 106.1 & 4.8 & 9.8 \\
\hline 25 th & 60.9 & 83.7 & 2.9 & 7.5 \\
\hline 75 th & 93.8 & 126.4 & 7.8 & 14.4 \\
\hline \multicolumn{5}{|c|}{ Control group $(n=39)$} \\
\hline Median & 76.2 & 99.6 & 3.2 & 10.9 \\
\hline 25 th & 50.0 & 77.9 & 2.1 & 6.0 \\
\hline $75 \mathrm{th}$ & 95.2 & 124.4 & 5.4 & 12.8 \\
\hline $\mathrm{p}$ value & 0.33 & 0.51 & 0.13 & 0.57 \\
\hline
\end{tabular}


Table 5. MFI and PPP in patients with thromboembolism and controls after stimulation with TRAP-6 (medians and percentiles)

\begin{tabular}{|c|c|c|c|c|}
\hline \multirow[t]{2}{*}{ Marker } & \multicolumn{2}{|l|}{ MFI } & \multicolumn{2}{|l|}{ PPP } \\
\hline & CD62 & CD63 & CD62 & CD63 \\
\hline \multicolumn{5}{|c|}{ Venous thrombosis group $(n=49)$} \\
\hline Median & 254.1 & 253.3 & 42.0 & 42.0 \\
\hline 25 th & 189.5 & 198.6 & 30.6 & 37.5 \\
\hline 75 th & 332.7 & 320.1 & 49.8 & 47.5 \\
\hline \multicolumn{5}{|c|}{ Control group $(\mathrm{n}=39)$} \\
\hline Median & 266.1 & 265.0 & 39.4 & 39.6 \\
\hline 25 th & 204.0 & 200.7 & 35.0 & 36.3 \\
\hline 75 th & 378.0 & 330.0 & 48.5 & 49.9 \\
\hline $\mathrm{p}$ value & 0.48 & 0.62 & 0.89 & 0.53 \\
\hline
\end{tabular}

\section{Discussion}

An increased or disturbed activation and aggregation of platelets is widely accepted to play a major role in the pathophysiology of arterial thrombosis and is related to vascular disease. Flow cytometry has been increasingly used for specific characterization of phenotypic alterations of platelets, which are related to prothrombic syndromes like acute coronary syndrome, stroke, diabetes, the immune type of heparin-induced thrombocytopenia and the antiphospholipid syndrome [6-10].

Experimental animal flow models have shown that even venous thrombosis induced by vessel wall damage is both coagulation and platelet dependent [11]. The antiplatelet agent ticlopidine revealed a potent antithrombotic effect in such a model [11], and aspirin was found to be as effective in reducing the thrombus generation as low molecular weight heparin under flow conditions [12].

Receptor-mediated activation of circulating platelets subsequently leads to changes of their membrane phospholipid distribution. These phospholipids provide procoagulant conditions by formation of prothrombinase and tenase complexes, which induce generation of thrombin and factor Xa $[13,14]$.

Our case control study is the first to evaluate platelet activation in patients with a history of spontaneous deep vein thrombosis by measuring platelet activation markers using flow cytometry. It seemed likely that in patients without known abnormalities of the plasmatic coagulation system, enhanced platelet function may be a relevant risk factor for venous thromboembolic events.
Our results do not demonstrate a significantly higher ex vivo expression of the established platelet activation markers CD63 and CD62 (P-selectin) in the group of patients with thrombosis. The migration of these two lysosomal and $\alpha$-granule membrane glycoproteins to the cell surface characterizes the secretion phase with release of platelet granula content. This process only takes place when high concentrations of agonists like ADP and thrombin are present [15]. In comparison, it is known that other activation-related platelet alterations like conformational changes of the fibrinogen receptor or formation of platelet-derived mircoparticles require less intensive stimuli. Taking this into account, it is a matter of debate whether the applied markers CD62 and CD63 are the most suitable ones with respect to an increased platelet activation suspected as a cause of venous thromboembolic events. Possibly, the measurement of other platelet alterations like shape change or surface expression of phospholipids would have achieved detection of platelet activation in the studied patients.

It has been speculated that an increased in vitro response of preactivated platelets to agonists may be present in prothrombotic syndromes $[15,16]$. Therefore, we investigated platelet activation marker status after stimulation with ADP and TRAP-6.

Such a phenomenon, which can be considered as 'priming', was not detectable in the platelets of patients with venous thrombosis. In parts, these findings are consistent with our previous investigations [18]. Using platelet aggregometry with high agonist concentrations, we found no platelet hyperreagibility at comparable amounts of ADP in the same populations of patients and normal donors [18]. Only TRAP-6 at a lower concentration of $2 \mu M$ was able to significantly differentiate between the investigated groups. In contrast, Breddin et al. [3, 4] described enhanced spontaneous aggregation in the PAT test, while Bick [19] and Mammen et al. [5, 20] observed an in vitro platelet hypersensitivity with similar concentrations of epinephrine and ADP in $13.2 \%$ of patients with a history of deep vein thrombosis. They concluded that platelet hyperreagibility may be a common cause of VTE [19].

There might be two reasons for the contradictory findings of these studies: flow cytometry reflects different platelet functions as aggregometry, and therefore, results can differ because of different methodology, e.g. the use of high agonist concentrations.

In addition, polymorphisms of receptors are thought to be a potential cause of platelet hyperreactivity. Michelson et al. [21] demonstrated a lower threshold of platelet 
activation measured by P-selectin expression, fibrinogen binding and GP IIb/IIIa activation for the GP IIIa PI ${ }^{(\mathrm{A} 2)}$ polymorphism, but found a different sensitivity to ADP only for low concentrations (0.5 and $1.0 \mu M)$.

If platelets display an 'all or none' activation response, the high agonist concentrations used in our study might have overcome differences of platelet reagibility which might have been detected using low agonist concentrations.
It is known that platelets participate in a complex manner in clot formation even in the venous system, but our data failed to show significant platelet activation in patients with venous thrombosis without predisposing factors. If only few patients with venous thrombosis possess permanently hyperactive platelets, larger numbers of patients are needed to identify these patients.

\section{References}

>1 Wu KK, Barnes RW, Hoak JC: Platelet hyperaggregability in idiopathic recurrent deep vein thrombosis. Circulation 1976;53:687-691.

-2 Breddin HK, Lippold R, Bittner M, Kirchmaier CM, Krzywanek HJ, Michaelis J: Spontaneous platelet aggregation as a predictive risk factor for vascular occlusions in healthy volunteers? Results of the HAPAG Study. Haemostatic parameters as risk factors in healthy volunteers. Atherosclerosis 1999;144:211-219.

$\checkmark 3$ Nowak-Göttl U, Kreuz WD, Hach-Wunderle V, Freund H, Güngör T, Ehrenforth S, Breddin HK, Kornhuber B: Hämostaseologische Veränderungen bei idiopathischen venösen Thrombosen im Kindes- und Jugendalter. Klin Päd 1991;203:424-428.

-4 Jäger W, Pietsch U, Krzywanek J, Breddin K: Die gesteigerte Plättchenaggregation bei Diabetikern und ihre Bedeutung als Risikofaktoren für Gefässerkrankungen. Verh Dtsch Ges Inn Med 1973; 79:1360.

5 Mammen EF, Barnhart M, Nanc R, Selik N, Gilroy J, Klepach GL: Sticky platelet syndrome: A congenital abnormality predisposing to thrombosis? Folia Haematol 1988; 118:361365.

66 Tschoepe D, Roesen P, Schwippert B, Gries FA: Platelets in diabetes: The role in the hemostatic regulation in atherosclerosis. Semin Thromb Hemost 1993; 19:122-128.

7 Hughes M, Hayward CP, Warkentin TE, Horsewood P, Chorneyko KA, Kelton JG: Morphological analysis of microparticle generation in heparin-induced thrombocytopenia. Blood 2000;96:188-194.
$>8$ Tomer A: Antiphospholipid antibody syndrome: Rapid, sensitive, and specific flow cytometric assay for determination of anti-platelet phospholipid autoantibodies. J Lab Clin Med 2002;139:147-154.

$\checkmark 9$ Tschoepe D, Schultheiss HP, Kolarov P, Schwippert B, Dannehl K, Nieuwenhuis HK, Kehrel B, Strauer B, Gries FA: Platelet membrane activation markers are predictive for increased risk of acute ischemic events after PTCA. Circulation 1993;88:37-42.

10 Zeller JA, Tschoepe D, Kessler C: Circulating platelets show increased activation in patients with acute cerebral ischemia. Thromb Haemost 1999;81:373-377.

11 Morishita K, Wada M, Kumada T, Tanaka T, Tomikawa M, Iwamoto M: Effect of ticlopidine and other antithrombotics on venous thrombosis induced by endothelial damage of the jugular vein of rats. Thromb Res 1991;63: 373-384.

12 Imbault P, Doutremepuich F, Aguejouf O, Doutremepuich C: Antithrombotic effects of aspirin and LMWH in a laser-induced model of arterial and venous thrombosis. Thromb Res 1996;82:469-478.

13 Ofosu FA, Liu L, Freedman J: Control mechanisms in thrombin generation. Semin Thromb Hemost 1996;22:303-308.
14 Solum NO: Procoagulant expression in platelets and defects leading to clinical disorders. Arterioscler Thromb Vasc Biol 1999; 19:28412846.

$\checkmark 15$ Gachet C, Hechler B, Leon C, Vial C, Leray C, Ohlmann P, Cazenave JP: Activation of ADP receptors and platelet function. Thromb Haemost 1997; 78:271-275.

16 Giesberts AN, van Willigen G, Lapetina EG, Akerman JWN: Regulation of platelet glycoprotein IIb/IIIa function via the thrombin receptor. Biochem J 1995;309;613-620.

17 Michelson AD, Ellis PA, Barnard MR, Matic GB, Viles AF, Kestin AS: Downregulation of the platelet surface glycoprotein Ib-IX complex in whole blood stimulated by thrombin, adenosin diphosphate, or in an in vivo wound. Blood 1991;77:770-779.

18 Weber M, Gerdsen F, Gutensohn K, Schoder V, Eifrig B, Hossfeld DK: Enhanced platelet aggregation with TRAP-6 and collagen in platelet aggregometry in patients with venous thrombosis. Thromb Res 2002;107:325-328.

19 Bick RL: Sticky platelet syndrome: A common cause of unexplained arterial and venous thrombosis. Clin Appl Thromb Hemost 1998; 4:77-81.

20 Mammen EF: Sticky platelet syndrome. Semin Thromb Hemost 1999;24:361-365.

-21 Michelson AD, Furman MI, GoldschmidtClermont P, Mascelli MA, Coleman L, Hamlington J, Banard MR, Kickler T, Christie DJ: Platelet GP IIIa PI (A) polymorphisms display different sensitivity to agonists. Circulation 2000;101:1013-1018. 